\title{
Os resíduos sólidos na civilização de consumo: desafio para a existência de um desenvolvimento sustentável
}

\author{
Solid wastes in the consumer civilization: challenge \\ for the existence of a sustainable development
}

\begin{abstract}
Vladimir Passos de Freitas
Mestre e Doutor em Direito pela Universidade Federal do Paraná (UFPR), professor de Direito Ambiental na Pontifícia Universidade Católica do Paraná (PUCPR), desembargador federal aposentado, ex-presidente do TRF da 4a Região, Curitiba, PR - Brasil, e-mail: vladimir@passosdefreitas.com.br
\end{abstract}

\section{Resumo}

O objetivo deste artigo é analisar, do ponto de vista jurídico, o problema dos resíduos sólidos no Brasil. $\mathrm{O}$ tema é pouco tratado. Não há sequer uma lei nacional que fixe linhas mestras para a matéria. Os problemas vêm se agravando. E nisto constata-se a omissão do Poder Público e dos administradores, nem sempre preocupados com tão grave problema. Faz-se especial menção às áreas contaminadas, tema quase ignorado pela doutrina pátria, apesar de estar se agravando pela descoberta de resíduos, resultado do mau acondicionamento de produtos tóxicos e químicos. Nesta mesma linha, analisam-se os aterros sanitários, tentativa ainda mal-sucedida de adequar-se o destino aos dejetos à proteção do solo e dos recursos hídricos. O estudo vale-se não apenas da análise das normas postas, mas 
também de atos administrativos, no caso de grande importância. Vale-se, também, das poucas lições da doutrina especializada, escassa no tema, bem como das notícias da mídia, inclusive da mídia eletrônica. Todas as referências são feitas na busca de encontrar-se solução que não impeça o desenvolvimento econômico que, apesar de necessário, deve ser sustentável. Finalmente, promove-se uma análise da jurisprudência dos tribunais sobre o tema, com foco na responsabilidade administrativa, civil e penal, citando-se os precedentes existentes.

Palavras-chave: Resíduos sólidos. Áreas contaminadas. Aterro sanitário. Responsabilidade administrativa, civil e penal. Desenvolvimento sustentável.

\section{Abstract}

The purpose of this article is to analyze, from the legal point of view, the problem of the solid waste in Brazil, which isn't usually dealt with. There isn't any national law setting guidelines for this subject. The problems are gradually increasing, due to the omission of the Public Power and the administrators, not always worried about such a serious problem. A special mention is made about the contaminated areas, a topic almost ignored by the national doctrine, in spite of the discovery of wastes, consequence of inappropriate packing of toxic and chemical products. Following this view, there is an analysis of the sanitary landfills, a still not successful attempt to adjust the waste disposal to the protection of the soil and the water resources. This article is based not only on the analysis of the norms, but also on the administrative acts, on the few existing lessons of the specialized doctrine and on the media, including electronic media. All the references are made aiming to find $a$ solution which doesn't prevent the economic development which, in spite of being necessary, must be sustainable. Finally, the article includes an analysis of court's decisions on the topic, focusing on the administrative, civil and criminal responsibility, with mention to existing precedents.

Keywords: Solid waste. Contaminated areas. Sanitary landfill. Administrative civil and penal responsibility. Sustainable development. 


\section{Introdução}

Os danos ambientais vêm se sucedendo através dos tempos e os estudiosos da matéria alertam sobre o perigo. Michel e Calliope Beaud com Mohamed Larbi Bouguerra (1993), em obra clássica sobre o tema, já observavam:

crescimento demográfico, procura incessante e desenfreada do bemestar, multiplicação artificial de necessidades, utilização de procedimentos técnicos cada vez mais poderosos: as capacidades de predação e de destruição de que os homens de hoje dispõem não têm comparação com aquilo que eram há um século. Consumir e deitar fora são os processos básicos da degradação das condições milenares de sobrevivência da biosfera, localmente primeiro, depois a nível regional e, por fim, a uma escala planetária. Em suma, a actual e crescente dinâmica de sobrevivência das sociedades atingiu uma tal dimensão, que provoca atentados cada vez mais graves contra as próprias condições de sobrevivência do nosso bom e idoso planeta, desta Terra que continua com o mesmo tamanho.

Albert Gore (1993), que foi vice-presidente dos Estados Unidos da América, escreveu obra intitulada $A$ Terra em balanço, na qual já alertava para o perigo do aquecimento do planeta. Ridicularizado na época, acusado de valer-se da mensagem ecológica para fins político-eleitorais, aquele autor viu suas previsões se confirmarem no início deste século XXI. Afirmou o estudioso, naquela época, que

as áreas da terra cobertas por florestas têm um papel fundamental na manutenção de sua capacidade de absorver dióxido de carbono $\left(\mathrm{CO}_{2}\right)$ da atmosfera, função básica para estabilizar o equilíbrio do clima em todo globo. Como já vimos no capítulo anterior, as florestas são fundamentais para a regulagem do ciclo hidrológico. Também estabilizam e conservam o solo, reciclam os nutrientes através da queda da folhagem e das sementes (e dos troncos, quando morrem) além de constituírem os habitats onde há mais alimentos para os seres vivos. Quando destruímos florestas, destruímos também esses habitats e os seres 
que deles dependem para viver. A controvérsia que foi levantada sobre a destruição e perda das terras úmidas, que também são habitats insubstituíveis para muitas espécies, é motivada pela mesma preocupação: a extinção de muitas espécies vulneráveis em pouco tempo, após o desaparecimento das terras úmidas.

Entre os inúmeros problemas ambientais que atormentam atualmente a humanidade encontra-se o destino dos dejetos criados pela civilização industrial. Como alerta o professor Plauto Faraco de Azevedo (2005),

o lixo é, em boa parte, subproduto do consumismo, sendo um tema fundamental a questão de seu destino final, nas megalópoles de nosso tempo. No Estado de São Paulo, pouco mais da metade das 18.000 toneladas de lixo domiciliar produzidas diariamente permanecem estocadas em condições inadequadas, representando riscos à saúde da população e ao meio ambiente.

Aí está, portanto, a questão primeira dos resíduos sólidos produzidos pela sociedade atualmente. Estamos diante de área do Direito Ambiental cuja responsabilidade não podemos, comodamente, lançar aos Estados, aos governantes, aos empreendedores ou a quem quer que seja. $\mathrm{Na}$ verdade, somos todos consumidores, habituados cada vez mais a um conforto do qual nem sequer cogitamos abrir mão. E a consequência disto é que este sistema de vida e de economia gera uma quantidade cada vez maior de dejetos, cujo destino se revela, na mesma proporção, mais problemático.

As espécies de resíduos sólidos variam conforme o local, podendo ser originárias de atividade simples, como a varrição e a coleta domiciliar, até outras de maior complexidade, como o lixo proveniente de hospitais. Sobre este último, uma reportagem do jornal Folha de São Paulo alertava que

o lixo de serviços de saúde é um reservatório de microorganismos potencialmente perigosos. Pode disseminar microorganismos resistentes no ambiente; causar ferimentos, por meio dos materiais radioativos e dos pérfuro-cortantes (agulhas, lâminas, bisturis, etc.); e provocar envenenamento e poluição, seja pelo derramamento de produtos como 
antibióticos e drogas tóxicas ou por elementos como mercúrio e dioxinas (ambos cancerígenos) (FOLHA de São Paulo, Cad. 5, 14/04/2002).

Entre os muitos problemas ambientais relacionados com os dejetos atualmente, encontra-se a falta de local apropriado para recebê-los. Para que se tenha disto uma pálida ideia, segundo notícia da imprensa, no Estado de São Paulo o município de "São Sebastião precisa percorrer 250 quilômetros para levar seu lixo a Tremembé, desde o fechamento do lixão da Baleia, em 2005" (FOLHA de São Paulo, Cotidiano, 03/01/2008. Prefeitos prevêem falta d'água em toda temporada no litoral de SP).

Pior ainda se revela a situação no sul da Itália, onde, segundo a imprensa, no início do ano de 2008 mais de 100 mil toneladas de resíduos se acumulam nas ruas das cidades, obrigando o exército a intervir no recolhimento do lixo da cidade de Nápoles e fazendo com que a população temesse pela própria saúde, inclusive se recusando a levar os filhos à escola (O ESTADO de São Paulo, Cidades/Metrópoles, 08/01/2008).

É verdade que existem tentativas de aproveitamento dos resíduos, por meio da reciclagem. Neste particular, há boas iniciativas que vão desde a educação ambiental (FUNDAÇÃO..., 1999) até a atividade dos catadores de papel, que acabam fazendo um serviço informal de recolhimento que diariamente trocam por dinheiro com intermediários nas cidades grandes e médias do País. Cumpre registrar que este sistema não existe apenas no Brasil, mas parece ser comum nos países latino-americanos.

Na verdade, as dificuldades para a disposição final dos resíduos, como ensina José Luiz Negrão Mucci (2005), devem levar em conta que é "cada vez mais importante a minimização do lixo na origem, incentivandose as medidas de reaproveitamento e reciclagem, para que a produção de resíduos sólidos seja diminuída". Em outras palavras, o ideal seria estancar a produção de material inútil ou de reduzida utilidade, como os sacos plásticos.

Apesar de ser grave o problema, do ponto de vista jurídico, a área de resíduos e saneamento é deficiente. A competência para legislar sobre o assunto é concorrente entre a União e os Estados membros, na forma do art. 24, inc. VI e XI da Constituição, que dá a estas pessoas jurídicas 
de Direito Público competência para editar leis sobre meio ambiente e saúde pública. No âmbito da União, aguardaram-se muitos anos até que se editasse uma lei com regras gerais sobre o tratamento dos resíduos. Com propriedade observaram Ilidia A. G. M. Juras e Suely M. V G. de Araújo (2006) que não se deve olvidar a "relevância da atuação da sociedade junto ao Congresso Nacional, para aprovar uma Política Nacional de Resíduos Sólidos justa, democrática e ambientalmente correta".

Omisso por longo tempo o legislador federal, alguns Estados editaram suas leis, com vigência no âmbito de seu território. É o caso do Paraná, que promulgou a Lei n. 12.493, de 22 de janeiro de 1999, que estabelece o tratamento e a destinação dos resíduos sólidos, pretendendo o controle da contaminação ambiental. Todavia, a política institucional de maior importância nessa área sempre foi conduzida pelos municípios, a quem a Constituição Federal, no art. 30, inc. I, deu poderes para legislar sobre assuntos de interesse local. Por vezes, a matéria era abordada na lei que cria o Plano Diretor, lei esta a que estão obrigados a editar todos os municípios que ultrapassem 20.000 habitantes, conforme art. 182 da Carta Magna. Em outros casos, o tratamento legal vinha dentro da lei municipal que trata da proteção ambiental, como ocorre em Curitiba, onde a Lei Municipal 7.833, de 19.12.1991, Capítulo III, artigos 12 a 22, trata do saneamento básico e resíduos sólidos. Outros, ainda, cuidavam do tema em leis esparsas, como Porto Alegre, onde a Lei Complementar 234, de 10.10.1990, instituiu o Código Municipal de Limpeza Urbana, e a Lei 9.192, de 8 de agosto de 2003, instituiu o Dia dos Resíduos Sólidos.

A fixação da competência legislativa como preponderantemente municipal criou alguns problemas. Um deles é que em regiões metropolitanas, com vários municípios sujeitos a políticas eventualmente antagônicas, o tratamento acabava sendo diverso, muito embora as dificuldades fossem as mesmas. Neste particular, o fato de os prefeitos pertencerem a partidos políticos diferentes podia dificultar ainda mais a solução.

Nestas condições, por ser sabidamente falha a legislação, a matéria foi sendo objeto de atos administrativos que acabam por suprir tal deficiência. Vale aqui citar, a título de exemplo: 1) Resolução Conama 
(Conselho Nacional do Meio Ambiente) n. 6, de 19 de setembro de 1991, que dispõe sobre incineração ou queima de resíduos de hospitais, portos e aeroportos; 2) Resolução RDC 217, de 21 de novembro de 2001, da Anvisa (Agência Nacional de Vigilância Sanitária), que regula a retirada de resíduos sólidos de bordo de embarcações; 3) Resolução Conama 313, de 29 de outubro de 2002, que cria o inventário nacional de resíduos sólidos industriais e dispõe em seu anexo I, entre outras exigências, sobre o preenchimento de ficha com informações sobre o destino dos resíduos sólidos gerados, bem como seu tratamento, reutilização, reciclagem ou disposição final fora da indústria; 4) Resolução 23/96 do Conama, que regulamenta, de acordo com a Convenção da Basileia (Dec. 875/93), a importação e uso de resíduos perigosos, estabelece os conceitos técnicos de cada espécie de resíduo, proíbe a importação de Resíduos Classe I e permite a importação de resíduos Classe II apenas para fins de reciclagem e reaproveitamento.

Finalmente, após longa e árdua discussão, foi promulgada a Lei 12.305, de 2 de agosto de 2010, dispondo sobre a Política Nacional de Resíduos Sólidos. Nela definiram-se termos técnicos (art. $3^{\circ}$ ), explicitando-se situações pouco conhecidas (v.g., art. $3^{\circ}$, inc. II: área contaminada: local onde há contaminação causada pela disposição, regular ou irregular, de quaisquer substâncias ou resíduos), fixaram-se os princípios (art. $6^{\circ} \mathrm{e}$ $7^{\circ}$ ), os instrumentos (art. $8^{\circ}$ ), o plano dos resíduos sólidos, daí especificando-se o papel da União dos Estados e dos Municípios (art. 16 a 19), dispôs-se sobre a responsabilidade compartilhada, ou seja, não apenas dos que geram mas também do poder público (art. 25 a 36), resíduos perigosos, instrumento econômicos e proibições (v.g., lançamento de resíduos no mar, art. 47, inc. I) e, no que toca às sanções administrativas, remeteu-se à Lei 9.605, de 1998, que, além dos crimes ambientais, trata da matéria nos artigos 70 a 76 .

\section{Depósitos de lixo ou resíduos}

De acordo com Fornari (2001), tem-se que 
lixo é denominação genérica de qualquer tipo de produto residual, restos, resíduos, detritos, despejos, procedentes de indústrias, comércio, lavoura e lares; matéria que sobra do processo de elaboração de alguma coisa ou que resulta da decomposição de algo, que se considera inservível, salvo para algum reaproveitamento.

Há várias espécies de lixo (ou resíduos), com diferentes consequências para o meio ambiente. Entre outros, é possível citar o lixo atômico, comercial, cósmico, hospitalar, oriundo de matadouro, doméstico, industrial, plástico e urbano. Evidentemente, o tratamento a ser dado a esses resíduos varia de acordo com o grau de periculosidade. Em um ponto extremo de cautela está o lixo gerado na obtenção de energia nuclear. No grau oposto, se encontrará lixo originado por papel utilizado, cuja reciclagem e aproveitamento são possíveis. Atualmente, o poder público e muitas empresas reciclam determinadas sobras. A classificação técnica de resíduos, de acordo com o grau de periculosidade, nos termos da Resolução Conama 23, de 12 de dezembro de 1996, e da NBR 10.004 ABNT é: Classe I - Resíduos perigosos, Classe II - Não inertes, Classe III - Inertes ou não solubilizáveis em certos parâmetros, dentre outros. (art. $\left.1^{\circ}, a, b, c\right)$.

O tratamento desses dejetos, até há poucos anos, era singelo e perigoso. Limitam-se as municipalidades a recolher o material, serviço esse posteriormente cedido a empresas especializadas, colocando-o em grandes depósitos. Esses locais, que se tornaram conhecidos por "lixões", não passavam por qualquer controle, estudo de impacto ambiental ou monitoramento. Segundo Edis Milaré (2004),

o impacto ambiental nesses casos, geralmente consiste em contaminação do solo por chorume - líquido percolado oriundo da decomposição de matéria orgânica - podendo atingir o lençol freático e cursos de água e supressão da vegetação. O item X da Portaria 053/79, do Ministério do Interior, proíbe esse tipo de disposição final.

A situação dos chamados "lixões" alterou-se em parte, mais recentemente, pela cobrança de medidas que as organizações não governamentais 
(ONGs) - que nada mais são do que a sociedade civil organizada - e o Ministério Público passaram a fazer dos gestores públicos, no caso, os prefeitos. Assim foi que surgiram os aterros sanitários. Paulo Affonso Leme Machado (2006, p. 551) lembra o conceito dado pela Sociedade Americana de Engenheiros Civis, para quem o aterro sanitário

é método de disposição de refugo na terra, sem criar prejuízos ou ameaças à saúde e segurança pública, pela utilização de princípios de engenharia que confinam o refugo ao menor volume possível, cobrindo-o com uma camada de terra na conclusão de cada dia de operação, ou mais frequentemente, de acordo com o necessário.

Porém, ressalve-se, os aterros sanitários constituem um passo à frente no trato do problema, muito embora não possam ser considerados uma solução definitiva.

\section{Áreas contaminadas}

Segundo os especialistas das áreas técnicas no sítio da Companhia de Tecnologia e Saneamento Ambiental (CETESB, 2008a),

uma área contaminada pode ser definida como uma área, local ou terreno onde há comprovadamente poluição ou contaminação causada pela introdução de quaisquer substâncias ou resíduos que nela tenham sido depositados, acumulados, armazenados, enterrados ou infiltrados de forma planejada, acidental ou até mesmo natural.

Os problemas da guarda e do destino dos resíduos perigosos surgiram com a industrialização e, como era de se esperar, nos Estados Unidos da América, por ser o primeiro país na ordem econômica mundial. Não interessa aqui desfiar os primeiros precedentes naquela nação, mas um caso merece ser citado como exemplo. Não apenas por ter sido objeto de ação judicial, como por ter sido divulgado por meio do cinema. Refirome ao processo que resultou na película A qualquer preço (A Civil Action), 
dirigida por Steven Zaillian, no ano de 1998, e que teve nos papéis principais John Travolta e Robert Duvall. O tema do filme, baseado em caso real ocorrido em Woburn, proximidades de Boston, Estado de Massachusetts, gira em torno de produtos químicos enterrados irregularmente por uma empresa, que contaminam as águas de um rio, gerando câncer na população local (United States District Court - District of Massachusetts. Civil Action n. 82-1672-S, Anne Anderson et al. contra W.R. Grace and Company, Beatrice Foods, Unifirst Company. Juiz Walter Jay Skinner, j. 10 a 26/05/1986).

Em boa parte do mundo, lugares para acomodar os resíduos, principalmente os mais perigosos, vão se tornando raros. Os países desenvolvidos procuram exportá-los para países com dificuldades econômicas, mediante compensação financeira. O fato foi exposto com clareza por François Roelants Du Vivier (1993, p. 253), ao mencionar que

durante muitos anos e, singularmente, no decurso da década de setenta, bem como no início dos anos oitenta, a Europa Ocidental assistiu ao turismo dos resíduos, sendo exemplo mais conhecido o 'passeio' que os 41 barris de dioxina proveniente do acidente de Seveso (Itália, 1976) deram, em 1983. Sabendo aproveitar as lacunas na legislação dos países vizinhos, muitas das deslocações e descargas de resíduos foram efectuadas, com toda a legalidade, em espaços membros da Comunidade Européia! A política de 'eliminação ao menor preço' não tem embaraços morais. Assim, a etapa seguinte consistiu na transferência dos resíduos perigosos para os países mais pobres, nomeadamente de África. Durante muito tempo pressentido, o tráfico dos resíduos tóxicos para os países em vias de desenvolvimento só veio a ser revelado, através de provas vergonhosas, pelo Acordo Europeu para o Ambiente, em 1988.

No Brasil, os problemas relacionados com áreas contaminadas vêm se sucedendo e merecem ser citadas, exemplificativamente, algumas notícias da imprensa:

a) $R \$ 8,5$ mi para limpar velho crime (O ESTADO de São Paulo, A26, 25/06/2006,). A superfície do Aterro Mantovani, no município 
de Santo Antonio da Posse, SP, possui fitas magnéticas, fraldas descartáveis, pedaços de plásticos e outros materiais e 15.000 toneladas de borra oleosa em uma lagoa, ficando a recomposição em vultosa soma de dinheiro; as indústrias que depositavam seus dejetos no local comprometeram-se a pagar a conta, conforme acordo firmado com o Ministério Público;

b) BB é multado por crime ambiental em SP (FOLHA de São Paulo, 18/08/2007, C6). O Banco do Brasil adquiriu a área localizada em São Paulo, capital, por dívida não quitada, e agora responde, como sucessor, pelo passivo ambiental;

c) Descoberta de resíduos de carvão põe em risco construção de Mauá (GAZETA do Povo, 03/08/2007, p. 18).

A preocupação com esses locais levou a Cetesb, do Estado de São Paulo, a promover o cadastramento de áreas contaminadas. Até novembro de 2007 foram cadastradas nada menos que 2.272 áreas contaminadas (CETESB, 2008b).

Esta modalidade de poluição do solo vem, aos poucos, atraindo a atenção da mídia. Segundo editorial do jornal O Estado de São Paulo a respeito do tema, "os postos de gasolina são responsáveis por 1.352 registros e a atividade industrial comprometeu 279 terrenos. O restante das áreas foi contaminado pelas ações poluidoras do comércio, dos depósitos de resíduos e acidentes com produtos tóxicos" (O ESTADO de São Paulo, A3, 27/12/2007). Como se vê, os postos de gasolina, com tanques velhos e sujeitos a vazamentos, são os principais causadores da contaminação do solo, além do conhecido problema que causam às águas subterrâneas.

Na área do Direito, o tema ainda é pouco estudado e discutido, muito embora venha sendo bem desenvolvido em outros campos científicos, como a saúde pública (MARKER, 2003). Buscando suprir a ausência de pesquisas na área jurídica, Ana Luiza Silva Spínola Krings (2007), com a experiência do exercício da função de advogada da Cetesb, sustenta que os municípios deveriam capacitar-se para assumir, com o órgão estadual, o controle das áreas contaminadas, observando que "dentre os 
municípios da região metropolitana, São Paulo e Santo André talvez sejam os únicos que inseriram em suas políticas públicas procedimentos específicos relativos ao tema". Em boa hora, a Lei 12.305/2010 conceituou área contaminada no seu art. $3^{\circ}$, inc. II, demonstrando, assim, a relevância do assunto.

Entretanto, em uma via mais preventiva que repressiva, buscase evitar a criação de novos resíduos sólidos ou, ainda, responsabilizar-se quem os cria pelo destino final. Esta seria uma forma de não criar novos aterros sanitários e de educar-se a sociedade para um consumismo menor e mais consciente, bem como atribuir às indústrias a responsabilidade por seus dejetos. Um exemplo de decisão no sentido de evitar a existência de novos resíduos foi dada pelo Juízo Federal de Marília, SP, em ação civil pública proposta pelo Ministério Público Federal (Justiça Federal, Subseção Judiciária de Marília, SP, proc. 20-02.61.11.001467-2, juiz Alexandre Sormani, em 31/01/2003, apud REVISTA de Direito Ambiental, v. 31, p. 375). A indústria de cerveja, que é das mais rentáveis no Brasil, formulou requerimento ao Ministério da Agricultura, objetivando que fosse permitido embalar o líquido em garrafas de polietileno tereftalato, mais conhecidas como garrafas PET. O procurador da República propôs ação judicial e o magistrado concedeu liminar, determinando que o registro da pretensão administrativa ficasse condicionado à emissão de licença ambiental fornecida pelo Ibama, e que este condicionasse a emissão da licença à adoção de medidas eficazes, estabelecidas em Estudo de Impacto Ambiental. A motivação da decisão judicial lastrou-se no fato de que o dano ambiental seria irreparável, pois o Brasil é o $4^{\circ}$ consumidor de cerveja do mundo, com 8,45 bilhões de litros por ano, e as garrafas PET não se dissolvem, causando grave dano ambiental. A ordem judicial impôs multa de $\mathrm{R} \$ 100.000,00$ pelo descumprimento a cada registro ou licença ambiental concedidos, e foi dada com efeitos para todo o território nacional. Houve recurso de agravo de instrumento, ao qual o Tribunal Regional Federal da $3^{\text {a }}$ Região negou provimento.

$\mathrm{Na}$ linha de que o criador responde pelos dejetos de seus produtos, há decisão pioneira do Tribunal de Justiça do Paraná, no sentido de que: 
Ação Civil Pública - Dano ambiental - Lixo resultante de embalagens plásticas tipo "PET" (polietileno tereftalato) - Empresa engarrafadora de refrigerantes - Responsabilidade objetiva pela poluição do meio ambiente - Acolhimento do pedido - Obrigação de fazer - Condenação da requerida sob pena de multa - Inteligência do art. 225 da Constituição Federal, Lei n. 7.347/85, artigos $1^{\circ}$ e $4^{\circ}$, da Lei Estadual n. 12.943/99, arts. $3^{\circ}$ e 14, $\S 1^{\circ}$, da Lei 6.938/81 (TJPR. Ap. Cív. 18652100, 8ª Câm. Cível, Relator Desembargador Ivan Bortoletto, j. 05/08/2002).

\section{Aterro sanitário}

O destino, guarda e tratamento dos resíduos têm merecido, na sua legislação interna, a atenção de alguns países. Na Alemanha foi editada uma lei específica sobre resíduos, a Lei de Fomento da Economia de Ciclo Integral e Segurança da Eliminação Ecocompatível de Resíduos, em 27 de setembro de 1994, BGBI, I, p. 2705. Referido texto legal determina que os resíduos sejam eliminados no território nacional ( $\$ 10$, item 3 ), estabelece obrigações fundamentais ( $(11)$, exigências mínimas ( $(12)$ e até obrigações dos proprietários de terrenos onde se acumulem resíduos (§ 14). A Bolívia, no Decreto Supremo 241/76, que regulamenta a sua Ley de Medio Ambiente, n. 1.333, de 27/04/1992, dispõe no art. $46^{\circ}$ sobre o passivo ambiental, que deverá ser gerido pelo Ministério de Desenvolvimento Sustentável e Meio Ambiente.

Na Suíça, tornou-se conhecido o caso do Aterro Kölliken, ${ }^{1}$ construído nos anos 70 para abrigo de resíduos perigosos. Apesar de ter sido empregada a melhor tecnologia, com o passar do tempo os resíduos vieram a contaminar as águas subterrâneas. Como relata Jeanne da Silva Machado (2006),

apesar de já terem sido gastos cerca de cem milhões de dólares com esses projetos, essas medidas não foram suficientes para conter a

1 Disponível em: http://www.smdk.ch, acesso em: 27/06/2009. 
contaminação em outras direções e outros projetos estão em fase de estudo ou estão iniciando a sua implementação, objetivando a construção de um sistema de drenagem hidráulica.

Este caso deixa flagrantes a relevância e dificuldade do tema. Nesse contexto surgiram os aterros de resíduos industriais, que são empreendimentos voltados à proteção e prevenção de contaminação ou qualquer forma de poluição, contando com avançadas técnicas de impermeabilização, com espessas camadas de argila compactada e geomembranas, ou mantas de $\mathrm{PAD}$, e que, por exigência de normas técnicas da ABNT, contam com drenos de monitoramento, coleta de percolados e estação de tratamento dos efluentes. Para aterros de resíduos perigosos vige a NBR 10.157, e para aterros de resíduos não perigosos, a NBR 13.896.

Registre-se, outrossim, a responsabilidade das empresas constituídas para a implantação dos aterros sanitários, ou seja, as que recebem os resíduos. Elas são responsáveis tanto pela adequada disposição como pela posterior manutenção dos dejetos. Isto faz com que o monitoramento de suas atividades seja matéria de interesse público e de permanente atenção dos órgãos ambientais. Não serão suficientes as auditorias internas que tais empresas realizem. Revela-se imprescindível, da mesma forma, o acompanhamento contínuo do órgão ambiental, face ao risco permanente de vazamento, com repercussões que podem vir a ser gravíssimas.

\section{Responsabilidade do poder público e dos administradores}

A prática do dano ao meio ambiente gera três tipos de responsabilidade: administrativa, civil e penal. Elas são autônomas e independentes, conforme se vê no contido no art. 225, $\S 3^{\circ}$ da Carta Magna. Isso significa que o infrator se sujeita a três distintas instâncias. Cumprindo a obrigação em uma delas, voluntariamente ou sob sanção, não estará isento de responder nas outras duas. Vejamos, separadamente, cada tipo de responsabilidade. 


\section{Responsabilidade administrativa}

A responsabilidade administrativa dos que praticarem dano ambiental relacionado com os resíduos, por força do disposto no art. 51 da Lei 12.305/2010, continua tendo por fundamento legal o art. 70 da Lei 9.605, de 12 de fevereiro de 1998, que considera infração administrativa ambiental "toda ação ou omissão que viole as regras jurídicas de uso, gozo, promoção, proteção e recuperação do meio ambiente". Isto significa que qualquer forma de participação importa em responsabilidade. Por outro lado, a Lei da Política Nacional de Resíduos Sólidos fornece, nos seus diversos artigos, subsídios para a análise de eventual falta administrativa. Por exemplo, o art. 20, inc. III dispõe que estão sujeitos ao plano de gerenciamento de resíduos sólidos as empresas de construção civil. Se elas não cumprirem este mandamento legal, o dispositivo servirá de suporte à aplicação da norma prevista na Lei 9.605/1998.

Por outro lado, os Estados da Federação e os municípios podem editar suas leis próprias, estabelecendo, inclusive, sanções. Todavia, caso não possuam lei própria e específica, poderão valer-se do regramento da Lei 9.605, de 12 de fevereiro de 1998, que é lei nacional, editada com fundamento no art. 24, inc. VI da Constituição da República.

No caso específico do mau gerenciamento ou destinação ilegal de resíduos, as sanções aplicáveis são as previstas no art. 72, que vão da simples advertência até a demolição de obra. Evidentemente, a pena de multa é a mais utilizada e de maior eficiência, vez que atinge o infrator em sua economia financeira. Os valores estão fixados no Decreto, 6.514, de $22 / 07 / 2008$, que no art. 62 , inc. V, estabelece a multa entre $\mathrm{R} \$ 5.000,00$ e $\mathrm{R} \$ 50.000 .000,00$.

Interessante observar que no artigo $4^{\circ}$ da Lei 9.605, de 12 de fevereiro de 1998, permite-se, inclusive, a desconsideração da personalidade jurídica da empresa quando esta constituir obstáculo ao ressarcimento de prejuízos causados à qualidade ambiental. Isto significa simplesmente que, se ela for insolvente, os sócios responderão pelos danos causados. Mas a melhor interpretação não é a de que isto se aplica automaticamente 
a todo caso de insolvência da pessoa jurídica. Na verdade, referido dispositivo dirige-se a casos em que a corporação atue de forma grave, reiterada, e não possa arcar com os ônus financeiros de sua conduta. Por exemplo, determinada indústria, sem dar ciência ao órgão ambiental, enterra seus resíduos e, com isto, causa contaminação do solo, prejudicando a saúde de moradores do local. Anos depois, vencida em ação civil pública e em ações individuais de indenização, revela-se insolvente. Nesta hipótese, os bens de seus sócios responderão pelas obrigações da empresa.

Finalmente, vale aqui citar acórdão do Superior Tribunal de Justiça, no qual se determinou a município que cumprisse o dever constitucional de proteção à saúde pública, desta forma ordenando que realizasse a coleta de lixo (STJ. Rec. Especial 575998/MG, $1^{\text {a }}$ Turma, relator ministro Luiz Fux, j. 07/10/2004).

\section{Responsabilidade civil}

A responsabilidade civil pelo dano ambiental é objetiva. Assim dispõe a Lei 6.938, de 30 de agosto de 1981, no seu art. 14, a qual foi não só recepcionada como ratificada pela Constituição de 1988, conforme art. $225, \S 3^{\circ}$. Evidentemente, toda a política nacional do meio ambiente se direciona no sentido de evitar, prevenir, a ocorrência do dano ambiental. Todavia, se ele vier a ocorrer, o causador será responsabilizado, independentemente da existência de culpa. E a jurisprudência mais recente do Superior Tribunal de Justiça deu nova interpretação ao art. $3^{\circ}$ da Lei 7.347, de 1985, ao concluir que o dever é cumulativo, reparar o dano e indenizar, e não alternativo (STJ. REsp 605.323/MG, $1^{\mathrm{a}}$ Turma, relator para o acórdão ministro Teori Zavaski, j. 18/08/2005).

Estabelecida esta premissa, vejamos a jurisprudência dos nossos tribunais nos casos de responsabilidade civil envolvendo resíduos sólidos. Os precedentes ainda são poucos se considerarmos a gravidade do assunto. O Tribunal de Justiça de São Paulo, julgando recursos de apelação em ação civil pública que buscava reparação civil de danos causados por incêndio 
em lixão, com destruição de uma reserva florestal, negou provimento aos recursos e manteve a condenação solidária do Município e da arrendatária da área, inclusive registrando que a responsabilidade era objetiva (TJSP. Ap. 167.181-1/8, relator desembargador Francisco Casconi, j. 04/06/1992, apud REVISTA dos tribunais, v. 687, p. 82).

A propósito, note-se que levantamento jurisprudencial do tribunal paulista apurou que aquela Corte Estadual, em 20 acórdãos envolvendo o tratamento de resíduos sólidos, julgou por 17 vezes procedentes ações intentadas com o objetivo de proteção do meio ambiente, e apenas em três casos concluiu pela improcedência (FREITAS, 2005a).

O Tribunal de Justiça do Estado do Paraná, julgando apelação cível contra sentença proferida em ação civil pública proposta pela Associação Movimento Nossa Terra (Amonter), contra o município de Rolândia, manteve a sentença de primeira instância que anulava decisão administrativa do órgão ambiental, por meio da qual dispensava a construção de aterro sanitário, face ao tamanho da área. O caso apresenta dois pontos de interesse. O primeiro é a ação civil pública ter sido proposta por uma ONG, algo pouco comum e que reforça a consciência da cidadania. O outro é que o Judiciário divergiu do entendimento da administração ambiental, que estabelecia tamanho mínimo para, só a partir daí, exigir o Estudo de Impacto Ambiental. Foi fixado o prazo de 90 dias para obediência da decisão judicial e multa diária de $\mathrm{R} \$ 1.000,00$ para a hipótese de descumprimento (TJPR. Ap. e Reex. Necessário 136.340-4, 2ª Câmara Cível, relator desembargador Ângelo Zattar, j. 30.04.2003.).

O Superior Tribunal de Justiça, julgando recurso que envolvia ação de vizinhos para que um município cessasse de usar local de uma antiga pedreira como depósito de lixo, concluiu que, além do Ministério Público ter legitimidade para propor ação civil pública, também os vizinhos podiam ingressar em Juízo na defesa de seus interesses (STJ. Recurso Especial 1998/0008167-4/RS, 2a Turma, relator p/ acórdão ministro Adhemar Maciel, j. 01/09/1998).

Saliente-se que a responsabilidade civil por dano ambiental é solidária, ou seja, todos que, de qualquer forma, tenham colaborado para 
a ocorrência do dano por ele responderão integralmente, facultado direito de regresso contra os demais partícipes. Esta é a posição da doutrina, cabendo citar, por todos, Fábio Dutra Lucarelli (1994, p. 8), para quem

dado o caráter de ordem pública de que goza a proteção do meio ambiente, instituiu-se a solidariedade passiva pela reparação do dano ecológico, o que significa dizer que, por exemplo, em um distrito industrial onde seja impossível individualizar-se o responsável pelo dano ambiental, todos serão solidariamente responsáveis.

A regra do artigo 1.518 do Código Civil determina a solidariedade na responsabilidade extracontratual e, não havendo definição sobre a proporção com que cada um contribuiu, torna-se imprescindível a prova técnica, que servirá também para estabelecer o nexo causal entre as atividades industriais e os danos, como para se reconhecer a real extensão dos prejuízos (STJ. 2 ${ }^{\mathrm{a}}$ Turma, REsp 11.074-0/SP, relator ministro Hélio Mosimann, j. 06.09.1993, DJ 11/10/1993). A esta decisão pioneira, outras tantas se seguiram na mesma linha, do STJ e de Tribunais de Apelação (STJ, REsp 295797/SP, $2^{\mathrm{a}}$ Turma, relatora ministra Eliana Calmon, j. 18/09/2001; STJ REsp 28222/SP, 2a . Turma, relatora ministra Fátima Andrighi, j. 15/02/2000; TJSP, Ap. Cível 5.578-5, Jacareí, 8ª Câm. de Direito Público, relator Antonio Villen, j. 04/03/1998; TJSC, Ag. Instrumento 2004.003959-0, relator des. Nicanor da Silveira. j. 23/09/2004).

Esta responsabilidade solidária não se limita ao dano incidental, mas também ao passivo ambiental deixado pelas empresas poluidoras às suas sucessoras. Como observa Patrícia Carvalho (2003), “o levantamento do passivo ambiental de empreendimentos consiste na apuração de todo o conjunto de obrigações efetivas ou meramente potenciais derivadas de desconformidades administrativas e ambientais da atuação humana sobre a propriedade". Finalmente, registre-se que no caso de dano ambiental não se indeniza apenas o prejuízo atual, ocorrido. Como bem esclarece Sílvio de Sálvio Venosa (2003), “a responsabilidade civil por dano ecológico vai mais além: todo prejuízo potencial, que pode advir no futuro, pode e deve ser coibido". Portanto, nesse diapasão, é aberta toda 
uma problemática a respeito de dano futuro, do impacto ecológico que a atividade possa vir a causar. Em razão desse aspecto, bem como dos interesses coletivos envolvidos, diminui-se a exigência de comprovação do nexo causal.

\section{Responsabilidade penal}

No âmbito penal, a poluição causada pelo lançamento ou mau gerenciamento de resíduos, está tipificada no crime previsto no art. 54 da Lei 9.605, de 12 de fevereiro de 1998, apenado com um a quatro anos de reclusão e multa. O tipo penal ambiental não consiste em produzir determinada quantidade de lixo, mas sim em dar-lhe destino que origine poluição significativa e que resulte ou possa resultar em danos. Em outras palavras, não constitui delito dar destino incorreto a determinado resíduo, por exemplo, lançando à via pública uma garrafa de plástico, mas sim em dar um fim aos dejetos que venham a pôr em perigo a saúde humana ou a causar mortandade de animais ou destruição significativa da fauna. Por exemplo, jogar restos de lixo hospitalar em um rio que serve de abastecimento à população e ficar demonstrado, pela perícia, que moradores do local tiveram exposta a risco sua saúde.

O crime de poluição é de perigo abstrato. Isto significa que não é necessário que ocorra qualquer dano. Basta que haja a simples possibilidade de risco, que nem precisa ser concreto, para que se consume a infração penal. O crime será qualificado e a reprimenda penal será aumentada para um a cinco anos de reclusão, nas hipóteses previstas nos incisos do $\S 2^{\circ}$ do referido dispositivo. Por exemplo, no caso do $\S 2^{\circ}$, inc. I, a contaminação de uma área, tornando-a imprópria para a ocupação humana. $\mathrm{Na}$ hipótese do inc. V, a referência é explícita à poluição por resíduos sólidos, líquidos e gasosos.

Outrossim, com respeito à prescrição dos referidos delitos, há que se ter em mira a regra do art. 108 do Código Penal. Ela deve ser contada pela pena em abstrato ou pela pena aplicada na sentença, conforme 
artigos 109 e 110 do referido codex. Portanto, na forma simples da cabeça do art. 54 da Lei 9.605/98, sendo a pena máxima de quatro anos, a prescrição ocorrerá em oito anos e, na forma qualificada, sendo a pena maior de cinco anos, dar-se-á a prescrição em 12 anos, tudo conforme art. 108, incs. IV e V da lei penal. Pela pena aplicada, prevista no art. 110, far-se-á o cálculo entre a pena imposta e o lapso de tempo transcorrido. Por exemplo, se o juiz impôs a sanção de um ano e seis meses de reclusão, a prescrição ocorrerá em quatro anos, conforme inc. V do art. 108. Assim, se entre a data do fato e o recebimento da denúncia, ou entre esta e a publicação da sentença condenatória, passaram mais de quatro anos, a prescrição deverá ser decretada pelo juiz, de ofício, tudo conforme art. 117 do Código Penal e 61 do Código de Processo Penal.

Ainda, é preciso atentar para a data do início da contagem da prescrição. Se o caso for de poluição por ação ou omissão, por exemplo, o lançamento de resíduos ao mar, a contagem se inicia da data da consumação do crime, nos termos do art. 111, inc. I, da lei repressiva. No entanto, se a hipótese for de enterro de material tóxico de forma irregular, contaminando a área, estaremos diante de crime permanente. Nessa espécie de delito, como ensina Fernando de Almeida Pedroso (1993),

atingido o bem jurídico pelo comportamento delituoso do sujeito ativo, verifica-se a projeção desse estado de lesão ao direito no decorrer do tempo, protraindo o crime seu momento consumativo, que, dessa forma, persiste, persevera e permanece após a ação e integração da figura típica.

Ocorrendo a persistência dos efeitos nocivos da poluição de forma indeterminada, a prescrição só começa a correr quando ela cessar, na forma do inc. III, do art. 111, do Código Penal.

A jurisprudência revela a existência de poucos casos envolvendo poluição por resíduos sólidos. Cita-se a título de exemplo acórdão do Tribunal Regional Federal da $4^{\mathrm{a}}$ Região que condenou pessoa física e jurídica por lançamento de esgoto não tratado em rio (TRF $4^{a}$ Região, Ap. 
Crim. 2000.72.04.001531-8/SC, relator desembargador federal Fernando Penteado, j. 23.02.2005).

Oportuno, ainda, lembrar decisão do Tribunal Regional Federal da $2^{\mathrm{a}}$ Região, no sentido de que,

restaurada a área onde fora depositado o lixo, segundo informações da Fundação Estadual de Engenharia do Meio ambiente (FEEMA), que, à época, autorizou os despejos no local pelo prazo de 90 (noventa) dias, não há como se perquirir da prática do delito capitulado no art. 54 da Lei 9.605/98, impondo-se o arquivamento do inquérito, uma vez presente a causa extralegal de exclusão de culpabilidade pela inexigibilidade de conduta diversa (TRF $2^{\mathrm{a}}$ Região, Inquérito 002000.02.01023182-RJ, relator desembargador federal Frederico Gueiros, in RTRF2 27/38).

\section{Os resíduos e o desenvolvimento sustentável}

A ordem constitucional brasileira, no art. 170, inc. VI, vincula a ordem econômica à proteção do meio ambiente. Traz aí a referência explícita que a sustentabilidade é requisito do progresso econômico, adotando postura do Programa das Nações Unidas para o Meio Ambiente (PNUMA). O desenvolvimento sustentável, objeto dos Princípios 4 e 23 da Declaração do Meio Ambiente de Estocolmo, em 1972, e dos Princípios 10 e 12 da RIO92, é a saída vislumbrada para a conciliação entre o progresso econômico, que significa empregos formais e arrecadação de tributos, com a preservação dos recursos naturais. Para Philippi Jr. et al. (2005, p. 795),

quando se discutem hoje os padrões de desenvolvimento sustentável, inevitavelmente passa-se por esse conceito que se refere à tecnologia ser apropriada ao lugar, às pessoas, aos recursos disponíveis, aos benefícios sociais e econômicos para a comunidade e ao nível de impacto ambiental tanto no consumo do capital natural como nos subprodutos e resíduos gerados pela sua implementação no sistema de produção local. 
Há quem, como Leonardo Boff (2002), rejeite o desenvolvimento sustentável de forma absoluta, sob o argumento de que são inconciliáveis o desenvolvimento e a destruição de recursos naturais. No entanto, poucas pessoas hoje se dispõem ao menor sacrifício, como abster-se do uso da energia elétrica ou do elevador, ainda que apenas uma hora por dia. Em outras palavras, é difícil, quase impossível, o retorno a uma vida mais simples e desprovida do conforto ofertado pelo progresso tecnológico.

No âmbito dos resíduos, vários são os conflitos que colocam em polos opostos desenvolvimento e proteção do meio ambiente. Por exemplo, a elevada produção de veículos automotores no Brasil dá emprego a milhares de pessoas, contribui para a arrecadação de tributos e para que as classes menos favorecidas possam ter acesso a um automóvel, regra geral por meio de financiamentos em longo prazo. Na outra face da moeda, as cidades veem cair a qualidade de vida de seus moradores, com a poluição do ar e sonora, decorrente do número crescente de veículos, bem como não conseguem solucionar seus problemas de tráfego, cuja tendência é de agravar-se.

Entrelaçado com o problema de excesso de veículos encontra-se o de seus resíduos. Não apenas as carcaças, mas tudo o que deles é utilizado. Por exemplo, a polêmica questão dos pneus, inclusive a importação de pneus usados. Neste particular, vale citar as palavras de Luís Alberto de Azevedo Aurvalle (2006, p. 164), ao afirmar que

a proibição de importação de pneumáticos usados é total, sendo, porém, possível a importação de pneumáticos remoldados procedentes exclusivamente de países integrantes do MERCOSUL. Em termos numéricos, tal brecha não constitui real preocupação em termos ambientais, considerando que, atualmente, esta categoria (remoldados procedentes do MERCOSUL) abrange menos de 5\% das importações de pneumáticos.

No entanto, a posição do Supremo Tribunal Federal é mais rigorosa, pois, ao julgar constitucional a legislação que proíbe a importação de pneus usados, vedou-a totalmente, inclusive para os países do Mercosul (STF, ADPF 101, Plenário, relatora ministra Carmen Lúcia, j. 24.6.2009). 
Na verdade, há que se buscar a solução no estímulo ou atribuição de ônus aos produtores, a fim de que deem destino aos resíduos que produzem. Não haverá solução sem que se altere o processo produtivo, e isto só ocorrerá alterando-se a forma de produção. A atividade industrial visa ao lucro e não será apenas por bons propósitos que as práticas mais rentáveis serão mudadas. É preciso que o poder público estabeleça regras comuns a todos, com vantagens a comportamentos que preservem os recursos naturais, pois, a partir daí, o próprio empreendedor encontrará, por meio da tecnologia, formas de conciliar a diminuição de custos e de proteção do meio ambiente. E mais: estimulando economicamente por um lado, deverá o Estado, da mesma forma, atribuir responsabilidade administrativa aos que não se adequarem às regras de responsabilidade pós-consumo.

Finalmente, registre-se que o termo "desenvolvimento sustentável" ainda não se incorporou nos precedentes dos Tribunais. Como já afirmei,

isso não quer dizer que a magistratura brasileira não estivesse preocupada em respeitar as duas vertentes em jogo, desenvolvimento, com reflexo em empregos e promoção social, mais meio ambiente. O que se quer dizer é que os juízes, ao julgar as causas ambientais, regra geral, atrelavam desenvolvimento à preservação dos recursos naturais e artificiais, porém não utilizavam a expressão 'desenvolvimento sustentável’ em seus votos ou sentenças (FREITAS, 2005, p. 241).

\section{Conclusões}

Afirmar que o tratamento dos resíduos é prioridade no controle da poluição do meio ambiente é desnecessário. Esta faceta da proteção ambiental representa, quiçá, o lado mais esquecido da proteção jurídica ambiental. De qualquer forma, é possível concluir que:

1) revela-se de grande importância o fato de ter sido aprovado o Projeto de Lei n. 5.296/2005, que por longo tempo tramitou no 
Congresso Nacional, convertendo-se na Lei 12.305, de 2 de agosto de 2010, tratando do Plano Nacional de Resíduos Sólidos;

2) enquanto os municípios não adotam uma política integrada e eficiente no tratamento dos resíduos, é oportuno que o Ministério Público atue, de forma coordenada, no âmbito de todo o território do Estado, objetivando pôr fim aos chamados "lixões", ainda existentes;

3) é importante, principalmente nos Estados mais industrializados, que se faça um levantamento das áreas contaminadas, publicando-se nos sites dos órgãos ambientais e averbando-se ao lado das matrículas nos Cartórios de Registro de Imóveis, evitando-se, assim, que compradores adquiram referidos imóveis e neles instalem indústrias ou construam habitações populares;

4) é essencial que o poder público exerça permanente fiscalização dos aterros sanitários, sob pena de improbidade administrativa nos casos de omissão;

5) nos casos de infrações à legislação existente, ainda que não específica, é importante que seja apurada a responsabilidade dos infratores, sejam agentes do serviço público, sejam particulares;

6) finalmente, para um futuro que se espera seja próximo, será necessário passar ao produtor o ônus de dar um destino aos resíduos que produz, vinculando esta despesa ao lucro auferido com a sua atividade.

\section{Referências}

ASSOCIAÇÃO BRASILEIRA DE NORMAS TÉCNICAS - ABNT. NBR 10.157. Apresentação de projetos de aterros sanitários de resíduos sólidos urbanos. Rio de Janeiro, 1981.

ASSOCIAÇÃO BRASILEIRA DE NORMAS TÉCNICAS - ABNT. NBR 13.896. Construção de poços de monitoramento e amostragem - procedimento. Rio de Janeiro, 1981. 
AURVALLE, L. A. de A. Importação e pneus usados e remoldados. Revista de Direito Ambiental, v. 41, n. 11, p. 164, jan./mar. 2006,

AZEVEDO, P. F. de. Ecocivilização: ambiente e direito no limiar da vida. São Paulo: Revista dos Tribunais, 2005.

BEAUD, M.; BOUGUERRA, M. L.; BEAUD, C. Estado do ambiente no mundo. Lisboa: Instituto Piaget, 1993.

BOFF, L. Um ethos para salvar a Terra. In: CAMARGO, Aspásia et al. (Org.). Meio ambiente Brasil. São Paulo: Estação Liberdade, 2002.

BRASIL não trata lixo de serviços de saúde. Folha de São Paulo, Cad. 5, 14 abr. 2002. Disponível em: <www.nuclear.radiologia.nom.br/politica/abril02/140402. htm>. Acesso em: 20 dez. 2003.

BREMBATTI, K. Descoberta de resíduos de carvão põe em risco construção de Mauá, 2007. Gazeta do Povo, 3 ago. 2007. Disponível em:<http://www.gazetadopovo. com.br/economia/conteudo.phtml?ema=1\&id=684431 >. Acesso em: 20 abr. 2009.

CARVALHO, P. Da avaliação do passivo ambiental. Revista de Direito Ambiental, ano 8, n. 32, p. 216-226, out./dez. 2003.

COMPANHIA DE TECNOLOGIA E SANEAMENTO AMBIENTAL - Cetesb. Companhia Ambiental do Estado de São Paulo. O que são áreas contaminadas. Disponível em: <http://www.cetesb.sp.gov.br/Solo/areas_contaminadas/areas.asp >. Acesso em: 17 jan. 2008a.

COMPANHIA DE TECNOLOGIA E SANEAMENTO AMBIENTAL - Cetesb. Companhia Ambiental do Estado de São Paulo. Cadastro de ACS. Disponível em: 〈http://www.cetesb.sp.gov.br/Solo/areas_contaminadas/cadastro.asp〉. Acesso em: 17 jan. 2008b.

FORNARI, E. Dicionário prático de ecologia. São Paulo: Aquariana, 2001. p. 149. FREITAS, G. P. de. A jurisprudência do Tribunal de Justiça de São Paulo em matéria ambiental. Campinas: Millenium, 2005. 
FREITAS, V. P. de. A constituição e a efetividade das normas ambientais. 3. ed. São Paulo: Revista dos Tribunais, 2005.

FUNDAÇÃO O Boticário de Proteção à Natureza. Reduzir, Reciclar, Reutilizar. São José dos Pinhais: Fundação O Boticário de Proteção à Natureza, 1999. Cartilha. GORE, A. A terra em balanço: ecologia e o espírito humano. Tradução de Elenice Mazzilli. São Paulo: Ugustus, 1993. Discurso.

JURAS, I. da A. G. M.; ARAÚJO, S. M. V. G. de. Uma lei para a política nacional de resíduos sólidos. Revista de Direito Ambiental, v. 43, n. 11, p. 131, jul./set. 2006.

KRINGS, A. L. S. S. A inserção das áreas contaminadas no planejamento urbano municipal: desafios e tendências. 2007. Projeto de pesquisa ao Programa de Pós-Graduação em Saúde Pública da Universidade de São Paulo, para obtenção do título de doutor, orientação professor Arlindo Philippi Jr., apresentada em 20 dez. 2007. p. 26.

LUCARELLI, F. D. Responsabilidade civil por dano ecológico. Revista dos Tribunais, v. 700, p. 7-29, 1994.

MARKER, A. A revitalização de áreas urbanas degradadas: políticas, instrumentos e incentivos no cenário internacional. São Paulo: GTZ, 2003.

MACHADO, J. da S. A solidariedade na responsabilidade ambiental. Rio de Janeiro: Lúmen Júris, 2006.

MACHADO, P. A. L. Direito ambiental brasileiro. 14. ed. São Paulo: Malheiros, 2006.

MILARÉ, É. Direito do ambiente. 3. ed. São Paulo: Revista dos Tribunais, 2004. MUCCI, J. L. N. Introdução às ciências ambientais In: PHILIPPI Jr., A; CAFÉ ALVES, A. (Coord.). Curso interdisciplinar de direito ambiental. São Paulo: Manole, 2005.

PEDROSO, F. de A. Direito penal. São Paulo: EUD, 1993. 
PHILIPPI Jr., A. et al. Curso interdisciplinar de direito ambiental. São Paulo: Manole, 2005.

VENOSA, S. de S. Direito civil: responsabilidade civil. 3. ed. São Paulo: Atlas, 2003. v. 4.

VIVIER, F. R. Du. Resíduos: um produto de exportação da Europa. In: BEAUD, M.; BEAUD C.; BOUGUERRA, M. L. Estado do ambiente no mundo. Direção Lisboa: Instituto Piaget, 1993. p. 253.

Recebido: 07/05/2009

Received: 05/07/2009

Aprovado: 19/07/2009

Approved: 07/19/2009 